\title{
SARRACENOS, MOROS, MUDÉJARES Y MORISCOS EN LA GALICIA MEDIEVAL
}

\author{
CARLOS ANDRÉS GONZÁLEZ PAZ ${ }^{1}$ \\ Instituto de Estudios Gallegos «Padre Sarmiento» (CSIC-Xunta de Galicia)
}

\begin{abstract}
Resumen
Con el presente artículo se pretende exponer una visión general de la presencia musulmana, conversa o no, en el territorio gallego durante la Edad Media, desde las primeras noticias conservadas datadas en el siglo VIII hasta finales del siglo XV; prestándole una especial atención a lo que hemos denominado «cuestión morisca», es decir, a la presencia de musulmanes convertidos al cristianismo en Galicia.
\end{abstract}

\section{Palabras Clave}

Musulmanes, Galicia, Edad Media.

\begin{abstract}
With the present article, we try to expose a general vision of the muslims, converted or not to the Christianity, in the Galician territory during the Middle Ages, from the first preserved news dated in the 8 th century until ends of the 15 th century; paying special attention to presence of Muslims who have turned themselves to the Christianity in this time.
\end{abstract}

\section{Key Words}

Muslims, Galicia, Middle Ages.

\footnotetext{
${ }^{1}$ Quisiera agradecer especialmente al Dr. D. César Olivera Serrano y también a la Dra. Da Gloria de Antonio Rubio del Instituto de Estudios Gallegos «Padre Sarmiento» (CSIC-Xunta de Galicia) y al Dr. D. Carlos Baliñas Pérez, profesor de la Facultad de Humanidades de la Universidad de Santiago de Compostela, la ayuda y los consejos ofrecidos a lo largo de la realización del presente artículo.
} 


\section{A MODO DE INTRODUCCIÓN}

Musulmanes, moros, sarracenos, mudéjares y moriscos son términos que se suelen utilizar muchas veces como sinónimos cuando realmente no lo son y consideramos importante realizar una definición previa de estos conceptos que utilizaremos a lo largo del presente artículo.

Los términos «musulmán» y «moro» podrían ser considerados como sinónimos imperfectos ya que se entiende por «musulmán» a todo individuo que profesa la religión musulmana, sin importar su origen geográfico mientras que «moro», dejando al lado la carga significativamente negativa que ha tomado el término a lo largo de los siglos, vendría a designar a todo seguidor de las creencias islámicas pero, también, se puede aplicar a los musulmanes que vivieron en la Península Ibérica desde el siglo VIII al siglo XV.

Un tercer sinónimo que también cuenta con la especial significación entre profesión de las creencias musulmanas y su presencia en territorio de la Península Ibérica, es el término de «sarraceno», el primero de los utilizados en las crónicas asturianas para referirse a los musulmanes andalusíes.

Por su parte, los musulmanes en territorio cristiano que mantuvieron sus creencias hasta la conversión forzosa del siglo XVI, son conocidos como «mudéjares» cuya presencia en territorio galaico es rastreable ya desde el siglo IX.

Por último, el término «morisco» tradicionalmente se aplica a los musulmanes convertidos forzosamente al cristianismo después de la revuelta mudéjar de 14991500 , pero esta definición consideramos que no recoge la verdadera dimensión histórica que la cuestión morisca alcanzó en la España medieval, que la minimiza y la relativiza, olvidando varios siglos de su existencia real en territorio cristiano.

Detrás del término morisco, que Joan Corominas ${ }^{2}$ indica que se registra ya en la documentación leonesa desde finales del siglo $\mathrm{X}$ aplicado a nombres de persona, se encuentra una realidad que, aproximadamente desde mediados de ese siglo, encontramos en la documentación galaica.

La realidad que subyace a este vocablo es la existencia en territorio galaico de hombres y mujeres, llegados de tierras peninsulares que van siendo sistemáticamente recuperadas del control musulmán, seguramente muchas veces como esclavos de guerra, que pasan a formar parte del tejido humano y económico de la Galicia medieval.

${ }^{2}$ COROMINAS, Joan, Diccionario crítico etimológico castellano e hispánico IV, Madrid 1954, 151. También en COROMINAS, Joan, Diccionari etimològic i complementari de la llengua catalana $\mathrm{V}$, Barcelona 1985, 797.

Cuadernos de Estudios Gallegos, Tomo LI, Fascículo 117, Santiago 2004. (Págs. 281 - 312) 
Muchas de estas personas permanecieron fieles a las creencias musulmanes pero otra parte, por ahora imposible de computar, con el paso del tiempo se fue incorporando a la comunidad cristiana a través del bautismo, muchas veces impulsados por sus domini o más tarde, por sus señores, o bien por la actividad evangelizadora sobre todo de las comunidades monásticas. Con el paso de los siglos su papel en la sociedad galaica también varía desde una supuesta condición esclava hasta, en algunos casos, la consecución de la plena libertad jurídica, pasando por los distintos tipos de servidumbre y por su práctica equiparación con los cristianos de su misma condición jurídica.

Aunque no hemos podido rastrear la presencia del término «morisco» en la documentación galaica hasta el siglo XIII, lo cierto es que ese concepto sí aparece representado en nuestra documentación, cuando menos desde mediados del siglo $\mathrm{X}$, como veremos en el presente trabajo.

La mejor aproximación al término «morisco» es aquella que nos ofrece la propia documentación medieval y en ella, incluso antes de la toma de la ciudad de Granada y la caída del poder nazarí, aparecen definidos como hombres y mujeres «que heran moros e se tornaron cristianos». Esta es la definición más clara de lo que era un "morisco» para un cristiano medieval y en base a esta realidad es lícito e, incluso, aconsejable, la aplicación de este término; huyendo de restricciones que se fueron construyendo a lo largo de los años y tendieron a acotar su significado a la población musulmano-conversa que permaneció en la Península Ibérica después de la citada revuelta mudéjar hasta su expulsión ordenada a principios del siglo XVII, cuando incluso la utilización de esta terminología en la propia documentación es anterior.

También veremos cómo se suelen utilizar calificativos para definir esa realidad que implica la existencia de musulmanes conversos en nuestro caso, en el territorio galaico, expresiones que van desde la simple indicación de que fue moro o que perteneció a los moros (entendido este término como indicativo de origen y pasado étnico y religioso); la indicación de su carácter de musulmanes bautizados o, ya en el siglo XV, la utilización de expresiones mucho más claras tendentes a indicar que tal sujeto era cristiano aunque había sido moro.

Todas estas fórmulas eran herederas de un término que tuvo mucho éxito en la legislación castellano-leonesa desde los siglos XIII y XIV al tratar el tema de los musulmanes conversos, los llamados tornadiços, es decir, los moriscos, aquellos musulmanes que se tornaban cristianos.

Como trataremos de mostrar a lo largo de las páginas siguientes, la presencia de musulmanes, conversos o no, en el territorio gallego es antigua y, muy posiblemente, más continua de lo que aquí hemos conseguido reconstruir. 
Otro punto que debemos aclarar previamente es la cuestión de la presencia de moriscos en la España septentrional. Como punto de partida recogeré unas palabras de unos de los grandes conocedores de la cuestión morisca en España como es Mikel de Epalza: «Aparte de los territorios cantábricos desde Galicia a Guipúzcoa, donde no están documentados, los hallamos en toda Castilla la Vieja, con la excepción de León y Astorga, y con especiales concentraciones en las regiones de Salamanca, Segovia y Valladolid» ${ }^{3}$.

El presente trabajo se aplica sólo al caso galaico pero en él se podrá comprobar cómo realmente sí existieron «moriscos» en territorio galaico y que el hecho de que no fueran cuantitativamente un grupo importante no significa que se deba minimizar la importancia de su presencia para el desarrollo del entramado humano y económico de la sociedad galaica desde la Alta Edad Media.

Primero nos detendremos unos instantes en su presencia antroponímica en la documentación:

- Musulmanes no conversos asentados en territorio galaico que conservan su nombre musulmán: Mahamud, Zahit, Zahim, Scahit, Zahaton, Iausar, Fetta, Rahama, Kerita, Aissima, Zahat, Eikar, Abdel, Gatel o Calaph.

- Musulmanes conversos con nombre de bautismo cristiano, acompañado de un «cognomen» indicativo de su origen étnico y/o religioso: Leodericum cognomento Abdela.

- Musulmanes conversos que presentan como nombre de bautismo un nombre cristiano, acompañado de un apodo indicativo de su origen étnico o religioso: Martinus Nigro o Pelagius Mauro.

- Musulmanes conversos con nombre de bautismo cristiano, acompañado de un apodo y de un indicativo de lugar de origen o de residencia: Petrus Nigro de Faro o Velascus Fernandi de Portugal.

- Musulmanes conversos con nombre y apellido cristiano y con un «cognomen» indicativo de su origen étnico y/o religioso: Fernandus Petri dictus Maurus. Esta modalidad antroponímica, de tomar nombre y apellido cristianos sólo la rastreamos a partir del siglo XIII. En este punto hay que señalar la existencia de cierta confusión respecto a la utilización de esta fórmula antroponímica, lo que obligó a varios monarcas del siglo XIV a desarrollar una dura legislación que impedía que los musulmanes no conversos tomaran nombres cristianos, para así diferenciarlos de aquellos que lo tomaban después de conver-

${ }^{3}$ EPALZA, Mikel de, Los moriscos antes y después de la expulsión, Madrid 1992, 71. 
tirse al cristianismo ${ }^{4}$. Esto implica que en estos casos sea más complicado dirimir su naturaleza morisca.

\section{MOROS, MUDÉJARES Y MORISCOS EN LA ALTA EDAD MEDIA}

Al poco tiempo de entrar en la Península Ibérica, cuando las tropas musulmanas se consideraron lo suficientemente seguras en la zona sur peninsular, entre los valles del Guadalquivir y del Guadiana, empezaron la conquista del norte ibérico, aprovechando el recorrido de las viejas cañadas ganaderas utilizadas ya en su momento por las legiones romanas para acceder rápidamente a estas tierras norteñas.

El avance musulmán fue sorprendente y ya en el año 712 Tariq, general de origen beréber al servicio de Muza ibn Nusayr, conquistaba Astorga y el mismo Muza, en el año 714, toma la ciudad de Lugo, cumpliendo un viejo deseo de conquistar esta zona de la Península Ibérica ${ }^{5}$.

La dominación musulmana de Galicia será efectiva desde ese momento hasta mediados de este siglo VIII aunque no existe acuerdo sobre el nivel de presencia musulmana en el territorio galaico.

Algunos autores defienden la hipótesis de que una vez dominado militarmente el territorio lo habrían abandonando, mientras que otros, coincidiendo con los anteriores en la escasa entidad de esta ocupación, sostienen que la presencia musulmana se abría traducido en el mantenimiento de puestos militares destinados a contener las posibles reacciones que podrían venir del territorio astur-cántabro que todavía no estaba bajo su control, territorio en el que ya estaba en ciernes el nacimiento del reino asturiano.

\footnotetext{
${ }^{4}$ Así se puede observar en el Ordenamiento otorgado el 15 de junio del año 1313 por la reina doña María de Molina y el infante D. Pedro en las Cortes de Palencia; en el Ordenamiento de las Cortes de Burgos de 23 de julio de 1315; en el Ordenamiento otorgado por de las Cortes de Valladolid para los concejos de Castilla, León y las Extremaduras el 8 de agosto de 1322 y, finalmente, en el Ordenamiento de las Cortes de Toro del 10 de septiembre de 1371.

${ }^{5}$ «Tiña Musa ben Nusayr afervoados anceios de penetrar na bisbarra de Galicia, asento dos infieis... precisamente cando non ficaba en España máis comarca que a Galicia que non estivera en poder dos árabes... Conquistou os castelos de Viseo e Lugo e alí detívose mandando exploradores que chegaron ata a Pena de Pelayo, sobre do mar Océano». AL-MAQQARI, Nafh al-Tib en SÁNCHEZ ALBORNOZ, Claudio, La España Musulmana I, Buenos Aires 1946, 43 tomado por BALIÑAS PÉREZ, Carlos, Do mito á realidade: a definición social e territorial de Galicia na Alta Idade Media (séculos VIII e IX), Santiago de Compostela 1992, 73.
} 
Los escasos datos disponibles nos hacen pensar en una presencia real de musulmanes en territorio galaico, presencia que se reduciría a las tropas asentadas sobre el terreno y a los miembros de la administración asentados en núcleos urbanos, como por ejemplo Lugo, quizás acompañados de sus respectivas familias.

Esta conclusión se deriva del hecho de que las crónicas asturianas y musulmanas coinciden en hablar de la existencia de una rebelión de las tropas beréberes asentadas en nuestro territorio frente a las elites árabes. Así lo recoge Carlos Baliñas basándose en la edición que Claudio Sánchez Albornoz realizó del Ajbar Majmúa: «Os muslines de Galicia e de Astorga resistiron longo tempo, ata que xurdeu a guerra civil de Abol-Jatar e Tsuaba. No ano 33 (750-751) foron vencidos e botados de Galicia, voltando a facerse cristiáns todos aqueles que estaban dubidosos na súa relixión e deixando de pagar os tributos (...) Mais cando a fame espallouse botaron tamén ós musulmáns de Astorga e doutras poboacións, e fóronse repregando tralas engrobias da outra cordeleira e ata Coria e Mérida no ano 36 (753-754)» ${ }^{6}$.

El texto narra la revuelta interna entre los ocupantes del territorio galaico, y deja entrever la referencia a la existencia de lo que parece ser un supuesto proceso de progresiva conversión de cristianos que habían permanecido en territorio controlado por las tropas musulmanas y que, una vez desaparecida esa dominación, regresaban al cristianismo ${ }^{7}$.

Es sorprendente cómo en poco más de treinta años, con una hipotética y supuestamente poco importante presencia de efectivos musulmanes en este territorio, se hable de cristianos que dudan de su religión, se acercan al islamismo para regresar al cristianismo en el momento en el que el dominio del territorio por parte de las tropas musulmanas desaparece.

Del texto se deriva que el cronista considera que esos hombres y mujeres no se habían convertido al Islam, no eran creyentes, pero que también iban progresivamente dejando de ser cristianos. La posible existencia, en el territorio de la Meseta Norte, de poblaciones cristianas conversas al islamismo, es decir, de muladíes, es un dato a tener en cuenta, ya que en siglos posteriores, tenderán a ser considerados como verdaderos musulmanes al serles aplicada la misma normativa que aquellos que descendían directamente de los invasores árabes o norteafricanos.

${ }^{6}$ SÁNCHEZ ALBORNOZ, Claudio, Despoblación y repoblación del valle del Duero, Buenos Aires 1966, 123 en BALIÑAS PÉREZ, Carlos. Do mito á realidade, 74-75.

${ }^{7}$ De confirmase esta noticia sería la primera noticia de la existencia de un grupo de personas, imposible de cuantificar, cuya situación político-religiosa se aproxima mucho al concepto de muladíes, es decir, de cristianos convertidos al islamismo que vivieron en territorio controlado por musulmanes durante la dominación y que después de la reocupación efectiva por parte de las tropas cristianas, tendieron a volver a abrazar la religión cristiana. 
En el texto también se refiere al hecho de que los cristianos, ante las luchas de poder existentes entre las tropas invasoras y ocupantes, dejaron de pagar tributos, quizás haciendo referencia al tributo que los cristianos que vivían bajo dominio musulmán, o sea, los mozárabes, tenían que pagar a las autoridades musulmanas para poder mantener sus cultos públicos y su organización eclesiástica.

Después de la desaparición de la presencia musulmana en tierras galaicas se inicia el proceso de integración de este territorio dentro del organigrama territorial del reino asturiano. Bajo Alfonso I (739-757) se integra efectivamente la costa cantábrica lucense, la «pars maritima Gallecie» de la documentación asturiana, en el reino astur.

Hay que señalar que en la documentación de esta época, conservada principalmente en las crónicas, no se cita la existencia de esos cristianos que habían abandonado el cristianismo y ahora regresaban a él, tal y como reflejan las crónicas musulmanas, quizás intentando ocultar una presencia, cuantitativa o cualitativamente más significativa, de los musulmanes en esta zona de la Península Ibérica.

De nuevo encontraremos la presencia y asentamiento de un cualitativamente importante grupo de musulmanes en territorio galaico, concretamente durante el reinado de Alfonso II (791-842). En este momento se produce en el sur peninsular una revuelta de beréberes y muladíes que debilita bastante las estructuras del emirato cordobés.

Aprovechando esta situación el gobernador de la ciudad de Mérida, Mahamud ibn Abd Al-Chabbar, se levanta contra el emir. Aunque éste consigue controlar la revuelta en el año 834, no consigue capturar a Mahamud quien, después de negociar con el rey asturiano, se asienta con su familia y tropas muy probablemente en la zona sur de la actual provincia lucense, cerca de Sarria, territorio ya incorporado a las estructuras de poder asturianas durante el reinado de Fruela I (757-768) ${ }^{8}$.

Aunque durante un tiempo el llamado «moro Mahamud» sirvió al rey asturiano frente al emir, parece ser que al final entró en negociaciones con él para intentar el regreso al sur peninsular. A modo de 'quintocolumnista', se alzó contra el rey cristiano que, ayudado por la nobleza galaica, lo cercó en el castro de Santa

8 962, mayo, 21. Sentario Ariániz y otros donan al monasterio de San Julián de Samos la villa de Alarín, en territorio de Sarria: «...donamus atque concedimus pro anima eius villam que fuit sua et est territorio Sarrie subtus muro de Mahamuth, prope villa regis que vocitant Elacin ad integrum per suos terminos,...». Santiago, A.H.U.S, Tumbo, fol. 14v. LUCAS ÁLVAREZ, Manuel, El Tumbo de San Julián de Samos (siglos VIII-XII), Santiago de Compostela 1986, doc. 32, 118-19. 
Cristina ${ }^{9} \mathrm{y}$, tras una dura batalla y después de tomar la fortificación, consiguió capturar a Mahamud a quien ordenó decapitar ${ }^{10}$.

Esto ocurrió en el año 840 y unos años más tarde, ya en la ciudad de Mérida, se produce un nuevo levantamiento en el año 869 contra el emir Abd Al-Rahman II, protagonizada por Abd-Al-Rahman Ibn Marwan, conocido como «el hijo del Gallego», posiblemente en referencia a su padre, Mahamud, el que había muerto en tierras gallegas, en el castro de Santa Cristina ${ }^{11}$.

Lo que no se nos cuenta en las crónicas es lo que pasó con las tropas que acompañaban a Mahamud. Seguramente muchos habrían muerto en el campo de batalla pero los restantes tan sólo habrían podido hacer dos cosas, o marcharse a tierras del sur después de pagar un rescate como se hacía con otros esclavos moros capturados en distintas batallas, o se habrían quedado en territorio cristiano, seguramente dispersos, para evitar así una nueva revuelta.

Por lo que se refiere a la segunda de las opciones podrían haber permanecido bien convertidos al cristianismo o bien manteniéndose como musulmanes en territorio cristiano, muy posiblemente como siervos.

Como acabamos de ver, la presencia musulmana en el territorio galaico en los dos primeros siglos de ocupación musulmana fue realmente significativa. Esta presencia se mantendrá en los siglos siguientes, con musulmanes asentados en nues-

${ }^{9}$ NOVO GUISÁN, José Miguel, «Santa Cristina do Viso (Incio, Lugo): ¿un castro antiguo o un castillo medieval?», Croa: boletín da Asociación de Amigos do Museo do Castro de Viladonga, 12 (2002), 37-40. Este autor identifica esta fortificación con la existente en la parroquia de Santa Cristina do Viso, situada en el lucense municipio de O Incio.

${ }^{10}$ SÁNCHEZ-ALBORNOZ, Claudio, Estudios sobre Galicia en la temprana Edad Media, A Coruña 1981, 143-57. En una donación que el rey Alfonso II realiza en favor de la Iglesia de Lugo datado el 27 de marzo del año 832, aunque seguramente extemporáneo a los hechos, podemos leer un resumen de lo acontecido: «Sed ipse ut erat fraudulentus, et deceptor, etiam contra me rebellione preparat, sicut ante fecerat contra Dominum suum: Et colligens secum sarracenorum multitudinem, eandem provinciam Galleciae depredare contur; colligens se in castrum quoddam, quod vocatum est ab antiquis Castrum Sancte Christine, cuius rei eventus cum ad me Oveto mandatum venisset, congregato exercitu, Galleciam properavit, ut de inimicis resisterem, et christicolas de manu sarracenorum eriperem, Deo exiliante. Veniens vero ad lucensem urbem cum omni exercitu, et ibi me in ecclesia Sancte Marie Deo orationibus commendans, altera die progressus sum ad pugnam: Castrum illus Sancte Christina obsedi, in quo erat adiunatio sarracenorum non minima, cum ipso capite, nomine Mahamut. Auxiliante itaque Deo castrum oppugnari, et omnium sarracenorum cervices ad terram postravi, ac delevi hismaelitarum insidias, interfecto ipso principe». FLORIANO CUMBREÑO, Antonio, Diplomática española del periodo astur: estudios de las fuentes documentales del Reino de Asturias (718-910) I, Oviedo 1949, doc. 40, 185-88.

${ }^{11}$ GARCÍA DE CORTAZAR, José Ángel, La época medieval, Historia de España, II, $9^{\mathrm{a}}$ ed., Madrid 1983, 99.

Cuadernos de Estudios Gallegos, Tomo LI, Fascículo 117, Santiago 2004. (Págs. 281 - 312) 
tro territorio bajo distintas figuras y estatus jurídicos, desde esclavos musulmanes hasta musulmanes conversos al cristianismo, es decir, moriscos. Esta presencia se constata ya en la documentación del siglo $\mathrm{X}$, ofreciéndonos, a lo largo y ancho del espacio galaico, una casuística muy interesante.

Antes de nada, al igual que hicimos al principio, resulta necesario aclarar ciertos conceptos. Tradicionalmente ha existido una diferenciación nebulosa del estatus jurídico de determinados grupos humanos dentro del organigrama general de la sociedad altomedieval galaica. Aunque no es este el lugar para intentar zanjar esta cuestión, sí nos interesa realizar ciertas aclaraciones.

$\mathrm{La}$ «sociedad» galaica del siglo X se caracteriza por ser una «sociedad» gobernada por el cambio respecto a los siglos inmediatamente anteriores, acelerándose el proceso de transformación en el modelo de la organización social y territorial.

Frente al crecimiento del siglo IX, pudo haber de un estancamiento, cuando no un retroceso, en la población galaica. El número de inmigrantes mozárabes, lusitanos o astur-cántabros llegados desde el sur y del este peninsular decrece, pero en cambio, éstos afianzan su instalación a lo largo del siglo X en el territorio galaico, hasta consolidar las innovaciones, formas y modelos de organización socio-territorial, gracias al acuerdo tácito de la propia monarquía astur-leonesa.

De esta forma en la primera mitad del siglo $\mathrm{X}$ podemos hablar de un estancamiento en el crecimiento poblacional iniciado un siglo antes, crecimiento que se recuperará en la segunda mitad del siglo, favorecido por el aumento de las posibilidades materiales de subsistencia. Esta segunda mitad de siglo se caracteriza por la expansión de las tierras cultivadas, de colonización y puesta en producción de nuevas tierras no tanto por la necesidad imperante del aumento de población como por las propias diferencias que van surgiendo en esta sociedad ${ }^{12}$.

Según Baliñas Pérez, en este período y con estas coordenadas, se produce la consolidación de la villa como modelo de organización socio-territorial y productiva. Aunque con ciertas reminiscencias en el modelo de villa galaicorromana, en tanto que explotación dominical, lo cierto es que se puede entender como creación de esta época, de la fusión de la tradición local con las aportaciones de los inmigrantes llegados tanto desde el norte como desde el sur peninsular. Estas villae deben ser entendidas tanto como unidades de explotación, es decir, como propie-

${ }^{12}$ BALIÑAS PÉREZ, Carlos, Do mito á realidade, 108 y ss. PALLARES, María del Carmen y PORTELA SILVA, Ermelindo, Edad Media, Historia de Galicia, $2^{a}$ reimpr., Madrid 1982, 79-83. 
dades territoriales, normalmente de gran tamaño, como unidades habitacionales, como verdaderas comunidades de aldea ${ }^{13}$.

Si hay un elemento que describe a la sociedad galaica del siglo $\mathrm{X}$ es su jerarquización y la diferenciación interna. La diferenciación básica se establece entre la condición servil o libre del individuo. Se trata de una diferenciación eminentemente jurídica que distingue a las personas en razón de su dependencia.

Dentro de los grupos no dependientes debemos distinguir a los señores o grandes propietarios rurales y a los pequeños propietarios libres y, en el otro lado, el conglomerado de situaciones que podemos denominar genéricamente como dependientes, encargados de poner en explotación las tierras del señor ${ }^{14}$.

Esta situación de falta de libertad jurídica y de dependencia señorial no debe confundirse con la esclavitud. Si bien es cierto que los individuos enclavados en este grupo no podían testimoniar delante de un tribunal y de los delitos que cometían eran responsables sus señores y aunque todavía existían esclavos, fundamentalmente prisioneros de guerra musulmanes o bien cristianos que perdían su libertad por impago de deudas, lo cierto es que se puede decir que desde el siglo VII el esclavismo no es un elemento definidor de la sociedad galaica.

Aunque la situación jurídica entre campesinos libres y dependientes, entre colonos y siervos, tenderá a equipararse con el paso del tiempo, todavía la servidumbre es un aspecto característico en la Galicia de los siglos IX y X, siendo su presencia mayor que en el resto de áreas cristianas peninsulares.

De forma general, dentro de este grupo de personas dependientes y jurídicamente no libres, es decir, de siervos, podemos distinguir a los servi idonei, los siervos domésticos, que solían realizar trabajos dentro de la residencia dominical o en sus aledaños, y los siervos rústicos o servi inferiores, aquellos que tenían que poner en producción las tierras del dominus. Dentro de esta estructura

${ }^{13}$ BALIÑAS PÉREZ, Carlos, Do mito á realidade, 74-75 y 209-215. Con matizaciones: GARCÍA DE CORTÁZAR, José Ángel, La sociedad rural en la España medieval, $2^{\mathrm{a}}$ ed., Madrid 1990, $22-$ 27, que considera que el modelo de comunidad de valle y el de villa-explotación entra en crisis ya en el siglo VIII y ya a finales del siglo IX tiende a ser substituido por el modelo de aldea como forma de organización social, y PALLARES, María del Carmen y PORTELA SILVA, Ermelindo, "Aproximación al estudio de las explotaciones agrarias en Galicia durante los siglos IX al XII», Actas de las I Jornadas de Metodología Aplicada a las Ciencias Históricas II, Santiago de Compostela $1975,95-113$, quienes en esta ponencia concedían a las villae galaicas una doble naturaleza explotacional y habitacional pero que más tarde matizarían esa vertiente económica de los asentamientos poblacionales.

${ }^{14}$ GARCÍA DE CORTAZAR, José Ángel, La época medieval, Historia de España II, 9a ed., Madrid 1983, 272-73. 
encontraremos las primeras referencias a la existencia de moriscos en la historia galaica.

En el año 911 el rey Ordoño II y la reina doña Elvira donan a la Iglesia compostelana, entre otros bienes, varios mancipiis de origen musulmán «Donamus etiam glorie uestre ex mancipiis, quos sancta intercessione uestra de gente hismaelitarum cepimus, nominibus: Froilanum, Leodericum cognomento Abdela, Froritum cognomento Abderramam cum sua muliere Maria et sua filia Guntina, Zahit, Zahim, Scahit, Zahaton, Iausar, Lallus, Fetta, Melchi, Zahit, Aloitus, Fare, Adosinda cognomento Anna, Teogundia cognomento Anza, Carrataim, Belita, Rahama, Kerita, Aissima cepta cum filia sua. Item et alios Zahat, Eikar, Abdel, Gatel, Calaph. Item Cahat, Alfarach, Abuzahat, Feta et Alazaht ${ }^{15}$. Esta es la primera constancia documental sobre la existencia de musulmanes conversos en Galicia.

Aparecen en total treinta y tres personas, entre hombres, mujeres y niños, todos siervos, mancipiis, dependientes del rey Ordoño II; todos son de origen musulmán y dependientes de la sede episcopal compostelana. No sabemos si, como en el caso de anteriores monarcas asturianos, la donación la realiza Ordoño II bien como monarca, en cuyo caso los siervos estarían previamente vinculados al trono asturiano, o bien como dominus, es decir, como gran propietario.

Entendemos que estos siervos podrían ser considerados como moriscos por dos razones. La primera porque hay que tener en cuenta que la donación la realiza el monarca al Apóstol Santiago y dice textualmente que «quos sancta intercessione uestra de gente hismaelitarum cepimus», que puede ser entendido en dos sentidos complementarios: el primero es que habían sido capturados en territorio musulmán y eran musulmanes y, el segundo, el de que habían sido separados de la fe musulmana gracias a la intercesión de Santiago Apóstol, por lo que se debería entender, por lo menos a parte de ellos, como cristianos.

El segundo aspecto que nos indica su naturaleza morisca es que muchos de ellos presentan nombres cristianos, seguramente como nombres de bautismo apareciendo como «cognomento», como apodo, su anterior nombre musulmán, lo que se puede considerar, sin duda, como indicativo de un reciente bautismo ${ }^{16}$. En esta situación nos encontramos con Leodericum cognomento Abdela, Froritum cognomento Abderahaman, Adosinda cognomento Anna o Tegundia cognomento Anza.

${ }^{15}$ LUCAS ÁlVAREZ, Manuel, Tumbo A de la Catedral de Santiago, Santiago 1998, doc. 21, 77-79.

${ }^{16}$ Sobre la utilización del nombre recomendamos: SUÁREZ BELTRÁN, Soledad, «Notas al sistema antroponímico asturiano en los siglos X al XII», Antroponimia y Sociedad: sistemas de identificación hispano-cristianos en los siglos IX a XIII. Santiago y Valladolid D.L. 1995, 121-32. 
Por último tenemos que señalar el hecho de que uno de ellos, Leodericum aparece casado con María y tienen una hija llamada Guntina. El hecho de que la mujer tome este nombre eminentemente cristiano, aunque este nombre no se generaliza hasta tiempo después ${ }^{17}$, y su presencia entre las musulmanas convertidas al cristianismo es poco corriente; unido al hecho de que especifique el nombre de la hija, un nombre de tradición goda, nos hace pensar que la esposa sea cristiana. Esto implicaría también necesariamente que Leodericum también lo fuera ya que los matrimonios mixtos estaban prohibidos y seriamente castigados.

Otra mención de la existencia de moriscos en Galicia se encuentra en un documento del monasterio de Celanova que su editor data entre el año 942 y 977, fechas que indican la consagración del monasterio celanovense y la muerte de San Rosendo, su fundador, respectivamente ${ }^{18}$. En este documento, que es una relación de pistoribus al servicio de San Rosendo, aparecen varios ejemplos que deben ser destacados.

En primer lugar nos encontramos con «Salvador Rodesindiz fuit maurus et habet quinque filios, Petro Salvadoriz, et Pelagio, et Ero, et Audesinda, et Usorio» ${ }^{19}$, es decir, el obispo San Rosendo de Celanova tenía un siervo doméstico, que trabaja como pistor para él, que había sido moro y que tenía cinco hijos. Tanto él como su descendencia presentan nombres cristianos pero lo que nos indica su naturaleza morisca es el hecho de que se utilice en el documento un pretérito perfecto para indicar que había sido maurus, que había sido musulmán, lo que implica necesariamente que ya no lo era, al igual que sus hijos.

En contraposición a este caso tenemos el de un pistor, siervo doméstico también, que es definido como maurus, como musulmán. Así en el texto se dice «Fees mauro de Monte Corduba genuit Santio Fees et Gemondo Fees. Santio Fees genuit Fernando Ardaga et omnes filios de Fernando Ardaga et Vimara Sanchiz cum suis filiis, et Ausinda Fees genuit Fernando Sanchiz et Martin Sanchiz, et Marina, et Santio Sanchiz $\rangle^{20}$. Como vemos, frente al caso anterior en que sí suponemos que existió un abandono de la creencia musulmana, en éste todavía se puede especular con su permanencia en ella.

${ }^{17}$ PORTELA SILVA, Ermelindo y PALLARES MENDEZ, María del Carmen, «El sistema antroponímico en Galicia: Tumbos del monasterio de Sobrado (siglos IX al XIII)», Antroponimia y Sociedad: sistemas de identificación hispano-cristianos en los siglos IX a XIII. Santiago y Valladolid D.L. 1995, 40-41.

${ }^{18}$ ANDRADE CERNADAS, José Miguel, Tumbo de Celanova I, Santiago de Compostela 1995, doc. $158,222-26$.

${ }^{19}$ Idem, Tumbo de Celanova I, Santiago de Compostela 1995, doc. 158, 223.

${ }^{20}$ Idem, Tumbo de Celanova I, Santiago de Compostela 1995, doc. 158, 224. 
El origen de este siervo es incierto. Aunque en el documento se cita su procedencia del Monte Córdoba, topónimo que se podría identificar con el monte homónimo situado cerca de Coimbra, teniendo en cuenta la fecha del documento y la extensión en esta época de la reconquista cristiana, debería tratarse de algún musulmán que viviera en la Meseta norte, nunca más al sur de la línea del Duero, que hubiera llegado a Galicia como cautivo capturado en alguna campaña militar.

Aparece acompañado de sus hijos que han tomado el nombre paterno como apellido pero ya no se indica su condición de musulmán, como sí se hace con su padre. No se puede asegurar que sus hijos se hubieran convertido al cristianismo pero es lo más lógico teniendo en cuenta que ya los nietos de este Fees tienen todos nombre cristiano, abandonando así la referencia antroponímica a su origen musulmán. Lo que sí heredan sus hijos y nietos es la condición de siervos domésticos que tenía su padre y abuelo.

El 22 de septiembre del año 943, el mismo prelado, para remedio de su alma y de la de sus padres, el conde Gutierre y la condesa Ildaura, concede la libertad a Muzalha y a sus descendientes «nisi heredibus tuis qui uno modo tecum a nobis liberi sunt $\rangle^{21}$.

Tradicionalmente se ha visto a Muzalha como una esclava al servicio de San Rosendo y que por este documento es manumitida, otorgándole ciertas propiedades para que las trabaje en régimen de dependencia servil. Es decir, en Muzalha muchas veces se ha querido ver a una especie de servi casati galaica. Nosotros consideramos que esta interpretación debe ser, cuando menos, matizada.

En ninguna parte del documento se indica su condición de esclava sino que se dirige a ella como «liberte mee Muzalha», es decir, que Muzalha ya era liberta, y había sido previamente manumitida, bien porque ella hubiera sido esclava y el mismo prelado $\mathrm{u}$ otro propietario anterior, la hubiera manumitido, bien porque sus antepasados, seguramente esclavos de guerra, ya hubieran sido libertos puesto que tal condición jurídica se heredaba.

Lo que realmente consigue Muzalha es lo que podríamos denominar «libertad jurídica plena», definida en términos propios del derecho romano clásico, es decir, alcanza la libertad que disfrutaban los ciudadanos romanos «absolvimus te ab omni nexu servitutis qualiter detersa caligo servili clara in aulam ingenuitaits resplendeas, et non te liberam inter liberos statuo verum etiam inter ydoneos licentiam tribuo civium romanorum consequi privilegium $\rangle^{22}$.

${ }^{21}$ Idem, Tumbo de Celanova I, Santiago de Compostela 1995, doc. 172, 240-41.

${ }^{22}$ Idem, Tumbo de Celanova I, Santiago de Compostela 1995, doc. 172, 240. 
Además de liberarla en el sentido comentado, el obispo San Rosendo le entrega un conjunto de bienes «in Caldellas Pinaria media; in Sallarem de Geentum duas partes; in Bubale, Mauregati, Vizamondi et in pumares de Viduas et Fraxaneto; in Portucal villa de Leza, sub ea tamen ratione servata» ${ }^{23}$ para su sostenimiento y el de sus descendientes que también tienen la condición de libres.

Muzalha pasa así a formar parte del grupo de pequeños propietarios libres, aunque sigue vinculada de cierta forma a San Rosendo, porque le pide que cada día de Navidad coloque una vela en una iglesia y dea limosna a los pobres por la salvación de su alma, además de impedirle a ella y a sus descendientes que enajenen de cualquier forma el patrimonio concedido salvo que sea vendiéndoselo al monasterio de Celanova ${ }^{24}$.

Una nueva noticia en el siglo $\mathrm{X}^{25}$ sobre la existencia de una mujer musulmana, muy probablemente morisca, que alcanza la «libertad jurídica plena», la encontramos en el caso de la mancipia Iulia ${ }^{26}$. En este documento del Tumbo de Celanova podemos ver como doña Goldregoto y sus hijos conceden a su mancipia, llamada Julia, la libertad a través de una "scriptura ingenuitatis», tal y como se utilizó en el caso anterior.

Se trata de una sierva, seguramente doméstica, que es hija de padres musulmanes «quod fuerunt genitores tui de tribus Ismaelitarum tribu Salomonorum» aunque parece que ella no lo era, pues tiene nombre cristiano y alcanza la libertad plena, aunque éstos no sean datos suficientes para aseverarlo.

Al igual que en el caso de Muzalha, Iulia alcanza la libertad gracias a fórmulas que retrotraen a un pasado lejano, al del derecho romano clásico, el cual, al igual

\footnotetext{
${ }^{23}$ Idem, Tumbo de Celanova I, Santiago de Compostela 1995, doc. 172, 240.

${ }^{24}$ Una interpretación en esta línea puede encontrarse en SÁNCHEZ ALBORNOZ, Claudio, «Los libertos en el reino asturleonés», Viejos y nuevos estudios sobre instituciones medievales españolas III. Madrid 1976-1980, 343-44.

${ }^{25}$ Para la datación del documento: SÁNCHEZ ALBORNOZ, Claudio, «Los siervos en el Noroeste hispano hace un milenio», Viejos y nuevos estudios sobre instituciones medievales españolas III, Madrid 1976-1980, 1551, nota 86.

${ }^{26}$ «In Dei nomine. Ego Goldregoto una cum filiis meis tibi mancipia mea Iulia in Domino Deo eternam salutem. Dubium quidem non est sed multis manet notum eo quod fueurnt genitores tui de tribus Ismaelitarum tribu Salomonorum necnon etiam et ipsa supradicta domna Gota placuit nobis atque convenit et poorpia nobis accessit et spontanea mea volumtate ut pro remedio anime nostre vel de virum meum Adanaricum cognomento Marvan ut in die iudicii ante Domino mercede vel indulgentiam accipiamus, facimus tibi scripturam ingenuitatis vel restaurationis ut sis libera et obsoluta ab omni nexu vel fece servili ingenua cive romanum deexernimus ut ubi ut ubi volueris iuvendi, manendi, fovendi, maneat indubita posteritas. Neminem qui de te inicimus servicium vel patrocinio vel patrocinio retere nisi Deum et rege potestatis». ANDRADE CERNADAS, José Miguel, Tumbo de Celanova I, Santiago de Compostela 1995, doc. 361, 517.
} 
que el derecho canónico, comienzan en esta época una recuperación frente a la tradición jurídica hispanovisigoda.

Iulia pasa a ser libre, disfrutando de la misma libertad que disfrutaban los ciudadanos romanos aunque con la limitación, ya clásica, de quedar bajo el patrocinio o amparo de sus antiguos domini a los que queda vinculada de una forma un tanto abstracta «facimus tibi scripturam ingenuitatis vel restaurationis ut sis libera et obsoluta ab omni nexu vel fece servili ingenua cive romanum deexernimus ut ubi ut ubi volueris iuvendi, manendi, fovendi, maneat indubita posteritas».

\section{MUDÉJARES Y MORISCOS EN LOS SIGLOS CENTRALES (SIGLOS XI A XIII): SU PAPEL EN LA SOCIEDAD GALAICA}

Poco a poco se fueron difuminando las barreras existentes entre los sujetos jurídicamente dependientes de aquellos que no lo eran, tendiendo a fundirse en una sola categoría jurídica, la de los pequeños campesinos jurídicamente libres, convertidos muchas veces en colonos de sus propias tierras y la de los dependientes, o sea, la de los antiguos siervos domésticos y rurales, tendiendo a establecerse su diferenciación interna, fundamentalmente, en base a la extensión de su explotación.

Así pues, poco a poco se podrá constatar la desaparición progresiva de la servidumbre en el rural galaico desde este siglo XI al siglo XIII. Tienden a desaparecer las menciones documentales de moriscos o mudéjares en este territorio aunque como podemos ver a continuación, todavía se pueden encontrar algunas.

En torno al año 1000 se redacta en el monasterio de Celanova una relación de hombres que el prepósito Cresconio tiene en el territorio de Baroncelle (Ourense), apareciendo entre los existentes en Albarellos Gaudio nigro, con su hermana Del$\operatorname{gada}^{27}$. Se utiliza un nombre cristiano o cristianizado de bautismo, de tradición latina en este caso, al que se le añade un apodo, con funciones de apellido, relativo a una característica personal del portador, en este caso, creemos, como indicativo de su antigua condición de musulmana tanto a nivel étnico como religioso ${ }^{28}$.

En este caso se trata de siervos rurales que explotaban propiedades del prepósito Cresconio en este término de Albarellos pues en el documento podemos leer «homines de Baronceli quos tenuit ille prepositus domno Cresconio» ${ }^{29}$.

\footnotetext{
${ }^{27}$ Idem, Tumbo de Celanova I, Santiago de Compostela 1995, doc. 152, 216-17.

${ }^{28}$ EPALZA, Mikel de, Los moriscos antes y después de la expulsión. Madrid 1992, 17.

${ }^{29}$ Idem, Tumbo de Celanova I, Santiago de Compostela 1995, doc. 158, 222-226.
} 
A este mismo personaje, es decir, a Gaudio nigro, lo volvemos a encontrar en un inventario de homines de criatione del monasterio celanovés, realizado por Vermudo Eroptiz en el año 1026. En él podemos leer: «In Alvarelios Gaudio nigro sua iermana Delgada ${ }^{30}$. En este documento, el hecho de encontrarlo equiparado a los siervos cristianos, sumado a lo anteriormente indicado, nos lleva a refrendar la opinión de que este Gaudio es realmente cristiano. Por lo tanto, por esta razón, recibiría el mismo trato y se equipararía su condición al de resto de personajes que aparecen en el citado documento, puesto que ya se ha abandonado la vieja denominación de mancipi, heredera de la tradición jurídica romana.

Tanto cristianos como musulmanes son considerados como homines de criatione, una categoría de dependencia mucho más laxa, por lo menos en apariencia; una categoría en la que cada vez se encontrarán tanto pequeños propietarios libres que van cayendo en la servidumbre como aquellas múltiples categorías de siervos existente en la Alta Edad Media que, como podremos comprobar en el siguiente documento, todavía se pueden registrar en la documentación del siglo XI, pero cada vez con un carácter más residual.

Pocos años más tarde, concretamente el 1 de diciembre del año 1029, el conde Rodrigo Ordóñez realiza una carta de dote y donación para su esposa la condesa doña Toda. Además de una serie de propiedades inmuebles, le entrega una serie de «mancipios et mancipellas quos fuerunt ex gentes mahelitarum et agarini». Es decir, le entrega un conjunto de siervos, al parecer de naturaleza doméstica ya que no aparecen vinculados a ninguna de las villae que también le entrega en dote.

Antes habían sido musulmanes, tanto a nivel racial como religioso, pero que en la mayoría de los casos ya no lo eran, «quos fuerunt ex gentes mahelitarum et agarini», pues se habrían convertido en cristianos.

Muy posiblemente aquellos siervos, tanto hombres como mujeres, que presentan todavía nombre musulmán, no habrían accedido al bautismo y por ello no habrían cambiado su nombre, aunque también se pudo producir el caso de que, una vez bautizados, optaran por mantener su nombre musulmán, aunque esta última posibilidad es muy remota.

El listado incluye un total de veintisiete personas, tanto hombres como mujeres, algunos con nombre cristiano (de tradición goda o propiamente latina), aunque otros tienen nombre de origen musulmán, principalmente las mujeres: «Petro, Martino, Domengu, Halephe. Item post Alveidar, Maria, Gigenia, Marina, Semza, Zeida, Adosinda, Nomen Bono, et de avolengarum criazione parentum Petro Petriz,

${ }^{30}$ Idem, Tumbo de Celanova I, Santiago de Compostela 1995, doc. 468, 647. 
Sunana, Salamiro, Salomom, Godina, Orabona, Cidi et quator suos filios Galindo, Godina, Eilo, Matre, Trasmira, Godina, Zakarias, Golgregodo» ${ }^{31}$.

Poco antes de terminar el siglo XI, en el testamento de Gonzalo Vidragiliz datado en el año 1094, nos encontramos una nueva noticia de siervos moros en Galicia, aunque debido al mal estado del documento desconocemos su nombre y su condición religiosa, es decir, no hay certeza de su bautismo: «Et mando et absoluo illos mauros ab omni fece seruile sicut insu(...) Trudildi, ingenuos et liberos. Nomina hec sunt; Pelagio, Garcia et filiis suis Maria et suo filio Munio Petriz» ${ }^{32}$. El hecho de que presenten nombre cristiano es un buen indicativo de su probable naturaleza morisca aunque no se puede asegurar.

Se trata de una liberación testamentaria en la que Gonzalo Vidragiliz libera a un grupo de mauros, en el sentido de que dejan de ser siervos jurídicamente dependientes, seguramente domésticos, a ser hombres jurídicamente libres, «ingenuos et liberos». El mismo ejemplo, sólo que aplicado a la liberación de dependientes cristianos, se puede observar en muchos testamentos de esta época e, incluso, posteriores. Por esta similitud, tradicionalmente se ha querido ver en este grupo de mauros, un grupo de musulmanes conversos, es decir, de moriscos.

Llegados al siglo XII nos encontramos con uno de los documentos sobre moriscos en Galicia más interesantes que se encuentra en el Tumbo del monasterio de San Salvador de Sobrado dos Monxes (A Coruña), fundado en la Alta Edad Media por los Aloitiz, poderosa familia condal galaica, emparentada con los Osoriz y los Menéndez, los fundadores del monasterio de San Salvador de Celanova. En este documento se describe la genealogía, sobre todo descendencia, de un grupo de moriscos que llegaron a Sobrado dos Monxes comprados como siervos rurales, aproximadamente y como señala el autor de la transcripción, en el año $1150^{33}$.

${ }^{31}$ Idem, Tumbo de Celanova I, Santiago de Compostela 1995, doc. 457, 626-27.

${ }^{32}$ LÓPEZ FERREIRO, Antonio, «Colección Diplomática», Galicia Histórica, Año I, t. II, Santiago de Compostela 1901, doc. LXXXIV, 396-97. Según indica el transcriptor, el original se conservaba en el Archivo de San Martín Pinario, aunque allí ya no se encuentre depositado actualmente.

${ }^{33}$ Por su interés procedemos a incluir la transcripción completa del documento: «117?. GENEALOGIA SARRACENORUM S. ${ }^{\mathrm{TE}}$ MARIE SUPERADDI. Frater Pelagius Rivera duxit de Portugalia Ali Petrarium, et ipse maurus habuit vxorem nomine Zamoranam, et generunt filius et filias: Marinam Suariz, et Petrum Gil: et Thomam, et Ioannem Gatteira: et iste Ioannes natus es de alio mauro nomine Mafumate quem duxerat fatus Pelagius de Hospitio. De Marina Suarij et de Adan natus est Petrus Adan ferrarius: de alio Marito Ioanne Petri dictus Galafri, que fuit filius de Mafumate, quem duxit Abbas Martinus, furnario natus est Ioannes Ioannis, et Fernandus Ioannis ambo ferrarj. De alio homine habuit unam filiam quem vocavit Mariam de Ganantia. De Petro Gil Pelitario natus est Ioannes Petri ferrarius, et Ouruana Vxor de Ioanne Gateira. De Thoma Pelitario nata est Maria Thomas vxor de Dominico teixilano. De Ioanne Gateira pelitario nata est Marina 
Este texto presenta una gran riqueza en la información que aporta a los investigadores en esta materia, mas tan sólo destacaremos aquellos puntos más relevantes:

Ioannis dicta Gateira, et alia filia nomine Miragla. Thomas antequam baptizaretur vocabatur Gali et Petrus Gil, Papum et Ioannes Gateira Mafarichi: ista est generatio de Ali Petrario, et de vxore sua Zamorana. Frater Menendus Velasquit emit Ali Muogu textor que postea dictus Laurentius in baptismo. De isto et vxore sua Stephania natus est Ioannis Laurentij textor, et Vitalis Laurentij textor, et Lupa. De Ioanne Laurentij, et de vxore sua Martini filia de Bofada natus est Michael, et alius parvulus. De Vitale, et Vxore sua Maria Petri filia de Petro Nigro de Faro, qui fuit filius de Mufate natus est Ioannes Amorosu, et alia filia parvula. De Mafumat, quem duxit Abbas Martinus secum, natus est Petrus Petri de Faro dictus Nigrus, et vocabatur ante baptismum, Olejas: et Ioannis Petri Feira qui vocabatur Galafre, et Matheus, qui vocabatur Zaqunti. De Petro Nigro de Faro natus est Petrus Petri de Faro, et Maria Petri vxor Vitale. De Lupa et de marito suo Laurentio nate sunt tres filie: et de Matheo nati sunt duo filij Ioannis, et alia parvula. De Ioanne setario, et de Marina Suariz quos superius diximus. De Matheo quem superius diximus ista est casada Mafuneti furnario.

Dommus Didacus Velasquit duxit Pedruchi Petrarium, et iste genuit Martinum Porra, qui ante baptismum vocabatur Lupi; et fuit filus de una mulieri, que vocabatur Cornadessa. Iste Martinus Porra habuit vxorem galegam, et ingenuo genere, et genuit ex ea Mariam Martini, et Petrum, et Ioannem, et aliam parvulam.

Frater Menendus Velasquit duxit Ciprianus Dente, qui post baptismum ita dictus est, et vxorem nomine Maiorem, sic post baptismum vocatam, et genit Onegam Cipriani, et Mariam Cipriani, Mariolam cognomento. De Maria Martini Cirpiani natus est Ioannes Teixilanus, et Maria Petri vxor de Martino de Seria galego. Frater Menendus Velasquit emit Aligurdu in Villa de Touru: et iste Ali habuit vxorem nomine Fatina Regannada et ambo pagani mortui sunt: haberunt tamem unam filiam nomine Hobonam que post baptismum vocata est Maria Ioannis, et unum filum cui imposuerunt in baptismo nomem Michael. Hobona habuit maritum nomine Valentiam, que in baptismo Martinus Pelagij vocatus est, et habuerunt duos filios et unam filiam: Dominicus Martini teixalanus, et Maria Martini, et Ioannes Martini, Dominicus habuit Uxorem filiam Thomas, et genuit unam filiam Maria Dona uxor de Ioanne Fernandi carpentarij: Ioannes Fernandi carpentarius iermanus de Martino Porra fuit filius de Pedruchi, et de Agilina, que in baptismo Maria Petri vocata est; et ista Maria Petri habuit unam filiam nomine Mariam Ioannes filiam de Ioanne Palumbo petrario galego. Bofada et uxor sua Zeina fuerunt de patre domni Petri Vele, et dederunt illos fratribus Superaddi sui filij de Donno Vela, et Velascus Ferdinandi de Portugal. Iste Bofada genuit tres filios. Elvire Arie, et Mariam Martini et Laurentium. De Elvira et de Martino Vitrio natus Ioannes de Deus, et Petrus de Belu et Iordanus. De alio homine nomine Ioanne Calvo carpintario galego nati sunt duo filij. De Maria Martini natus est Fernandus, et Michael, et Petrus Dunzel. De Laurentio nate sunt tres filie, Amorosel, et Maria, et alia. De Petro Ordonij nata est Maria Ordonij natus est Fernandus Muniz filius de Munione Argeiru galegu. De Fernando Nigru que prius vocatus est Mafumate natus est Martinus Fernandi, et Elvira Fernandi. De Elvira Fernandi natus est Petrus de Meira filius de patre galego. De Martino Fernandi, et de una muliere de Regaria, et galega natus est unus puer parvulus. De Mafumate Texilina, qui in batismo vocatus est Martinus Menendi, quique, et postea conversus factus est nata est Marina Broca. De ista Marina nata est Maria Petri, filia de uno homine galegu: et alia filia de Ioanne Galafre ferrario: et alia filia de alio patre galegu, et vocatur ipsa filia Zebula. Ioannes Zada carpentarius venit de Portugalia, et habuit unum filius de muliere galega, et vocatur Petrus Maurus. Petrus Lufas sutor fuit filius de Urraca Vetula et genuit Ioannem Petri sutorem, et Martinum, et Michaelem, et Mariam Petri. Isti fuerunt filij de supradicto Lufas, et de matre galega. De Hahansi, 
- Se trata de una verdadera comunidad de musulmanes que fueron vendidos a la abadía de San Salvador de Sobrado dos Monxes para que trabajasen las tierras del monasterio tanto como siervos rurales como siervos domésticos. Se aplica este último calificativo sobre todo a los que tienen profesión conocida ${ }^{34}$, símbolo de su consideración dentro del conjunto de siervos del monasterio.

- En cuanto a su origen, el documento nos indica dos procedencias: el territorio portugués ${ }^{35}$ y las tierras zamoranas ${ }^{36}$.

- Aunque de origen religioso musulmán ${ }^{37}$, la mayor parte se bautizaron ${ }^{38} \mathrm{y}$

et de Zeina natus est Guillelmus Arias. De Guillelmo Arias, et de una galega nata es Serra et Ioannes Guillelmi, et Petru Guillelmi». VAAMONDE LORES, César, «Genealogía de los moros comprados por el monasterio de Sobrado con el fin de dedicarlos a cultivar las tierras de los monjes y a trabajar en diferentes oficios», Colección de documentos históricos del Boletín de la Real Academia Gallega, A Coruña 1915, doc. XXVIII, 89-91.

${ }^{34}$ Así se pueden destacar ejemplos como los de Ali Petrarium, que como indica su apellido era pedrero; Ioannes Ioannis y Fernandus Ioannis, dos hermanos que eran herreros; Ioanne Fernandi del que se nos dice que es carpintero o el caso de Ioannis Laurentij que se nos indica que es una especie de tejedor.

${ }^{35}$ Tenemos por ejemplo los casos de Velascus Fernandi de Portugal donde muy probablemente el topónimo se convierte en parte de su apellido como forma de indicar su origen, es decir, se convierte en antrotopónimo; de Ioannes Zada carpentarius venit de Portugalia, donde ya es explícito su origen al sur del río Miño y, el caso más claro que se encuentra en la primera línea del documento, Frater Pelagius Rivera duxit de Portugalia Ali Petrarium, es decir, que el monje Pelayo Rivera se trajo de Portugal a Ali Petrarium.

${ }^{36}$ Son dos los casos en que se nombran estas tierras. Así la esposa de Ali Petrarium es conocida como «Zamorana» y el monje Menendo Velasquit compró a Aligurdu en la villa zamorana de Toro. En esta villa castellana existió una comunidad morisca que alcanzó cierta representatividad social con personajes de influencia tan notable como Pelagius Mauro, quien es citado con ocasión de un intercambio entre el monasterio de San Leonardo (suponemos que el de San Leonardo de Yagüe) y el de Santa María de Oseira en la que además se citan como participantes de una donación anterior a la infanta Sancha y al conde Rodrigo y a su esposa la condesa Sancha, hija del conde Ponce, mayordomo del rey Fernando II de León: «Insuper et damus vobis cartulas donationis quas inde habebamus a comite, videlicet, Roderico et domina Sancia, filia comitis Pontii et filiis eius et domini Velae. Et ut controversia quae inter nos fuerat certo fine sit sopita et determinata, dattis nobis hereditatem vestram quam habebatis in locum de Touro in ves de Marvan cum omni iure suo, videlicet, cum hereditate quam dedit vobis infans domina Sancia, et illa quam dedit vobis Sancia Poncia, et ea quam dedit vobis Pelagius Mauro cum omnibus prestationubus et pertinentiis suis;...». ROMANÍ MARTÍNEZ, Miguel, Colección diplomática do mosteiro de Santa María de Oseira I, doc. 39, 47.

${ }^{37}$ En la primera de las líneas podemos leer como el monje Pelayo Rivera se trajo de Portugal a Ali Petrarium, indicando que «iste maurus habuit vxorem nomine Zamoranam».

${ }^{38}$ Son múltiples los casos que se pueden obervar en el documento por lo que señalaremos sólo un par de ejemplos. Así Ali Muogu «textor que postea dictus Laurentius in baptismo»; Ciprianus Dente así llamado «post baptismum» o su esposa llamada Maiorem también «post baptismum» o el caso de Honbona «que post baptismum vocata est Maria Ioannis». 
cambiaron de nombre ${ }^{39}$, seguramente animados por los monjes del monasterio de Sobrado, salvo en dos casos ${ }^{40}$.

- La utilización de los términos nigro y maurus, indica un origen racial, como un calificativo o apodo que en muchas ocasiones se usa para musulmanes conversos ${ }^{41}$

- Este documento demuestra la progresiva equiparación de los siervos de origen musulmán pero convertidos al cristianismo, con los siervos galaicos, cristianos de origen. Esto se manifiesta, sobre todo, en la celebración de matrimonios mixtos, ya que el matrimonio mixto entre personas de origen cristiano y musulmán como ya hemos comentado anteriormente, estaba seriamente condenado por la legislación de la época ${ }^{42}$.

- Por último destacaremos la liberación jurídica de uno de estos siervos, al que se le concede una «carta ingenuitatis» ${ }^{43}$.

Unos años más tarde, el 11 de abril del año 1163 , nos encontramos, entre los participantes en una venta, el testimonio de la presencia de otro musulmán, no sabemos si converso o no, en la documentación galaica. En la fecha señalada Petrus Testa, Nuno Pelaici y Pelagio Almuravide, con sus hijos e hijas, venden a Nuño

${ }^{39}$ Un ejemplo de esto lo encontramos, entre otros casos, en el de Fernado Nigro «que prius vocatus est Mafumate». En este punto hay que señalar que otro aspecto significativo del proceso de conversión de estos musulmanes en cristianos, es interesante la asunción como propio, por una parte de estos moriscos, del sistema nominal cristiano, por el cual el hijo tomaba como apellido el nombre del padre, así Maria Ordoni, morisca, tiene un hijo de Munione Argeiru «galegu», que se llama Fernandus Muniz o el caso de Maria Petri, también morisca, que tiene una hija con Ioanne Palumbo "petrario galego», que se llama Mariam Ioannes.

${ }^{40}$ Así en el documento que Ali y su esposa Fatina Regannada habían muerto «pagani», es decir, habían muerto como infieles no bautizados, algo que no pasa con su hija llamada Hobona porque se bautiza y se convierte en Maria Ioannis.

${ }^{41}$ Nos encontramos con el caso de Petrus Petri de Faro del que sabemos que llaman «nigro» (indicativo de origen racial y religioso) pero, unas pocas líneas a continuación, ya nos encontramos con este calificativo integrado en el nombre, denominándolo en dos ocasiones «Petrus Nigro de Faro». También aparece el caso de un musulmán llamado Mafumate que pasa a llamarse «Fernando Nigro» después de bautizarse. Lo mismo sucede con el calificativo, anteriormente racial e indicativo de credo religioso maurus, como en el caso del hijo de Ioannes Zada y de su mujer, llamado «Petrus Maurus» y que ahora tan sólo parece hacer referencia a un pasado relativamente cercano.

${ }^{42}$ Sirvan como ejemplos el matrimonio de Urraca Petri, musulmana conversa, que estaba casada con Martino de Seria galego; la unión entre Guillelmo Arias y «de una galega»; o los casos de Martino Fernandi quien tuvo varios hijos con «una muliere de Regaria, et galega» o de Elvira Fernandi quien tuvo un hijo llamado Petrus de Meira «de patre galego».

${ }^{43}$ Petro Ordonij es padre de Maria Ordonij y al padre, pero no a su hija, se le concede la condición de jurídicamente libre: «et isto Petro Ordonij dederunt cartam ingenuitatis, sed non filie». 
Fernández una heredad situada en tierra de Castela, bajo la iglesia de San Mamede, en las villas que se llaman Caxidaes y A Grova ${ }^{44}$.

Aquí vemos otro ejemplo de la utilización por parte de un musulmán, muy probablemente converso, de un nombre cristiano como nombre de bautismo y, como apellido, un indicativo de su procedencia gentilicia.

Quizás el aspecto más destacable sea la presencia de este probable morisco con su familia actuando de forma directa en la vida económica de la comunidad, pues vende propiedades que le pertenecen. Al igual que los judíos, los moriscos podían tener propiedades y participar en la vida económica siempre que ésta se mantuviese entre privados, no pudiendo participar en actos públicos, sobre todo jurídicos, ni como miembros activos ni como testigos, ya que lo tenían prohibido.

La progresiva identificación entre cristianos y musulmanes convertidos al cristianismo hace difícil encontrar referencias precisas a su presencia en nuestro territorio aunque, con todo, es posible seguir descubriendo algunas informaciones documentales.

Pasado ya el cambio de siglo, el 18 de julio de 1205, en la villa de Ribadavia, Fernando Fernández y su mujer Mayor Pérez venden a Fernando Peláez una viña en el lugar de Veronza. Entre los testigos aparece un Martinus Nigro que sigue la tónica ya conocida de adoptar en el bautismo un nombre cristiano, aunque el apellido o apodo revele su origen ${ }^{45}$.

Como en el caso anterior, nos encontramos a un Petro Mouro que actúa como testigo en una venta que realiza García Núñez al abad del monasterio de Santa María de Oseira de todo lo que poseía en la villa de Castañeira ${ }^{46}$.

Este mismo Petro Maurus, junto a otros cinco hombres, aparece recibiendo en foro del monasterio de Santa María de Oseira una heredad en la granja monacal de Mato, en Cameixa (Ourense) en el mes de septiembre del año 1213: «Notum sit tam presentibus quam futuris quod nos Petrus Maurus, Fernandus Arie, Petrus Sesnandi, Arias Martini, Rodericus Alfonsi, Suerius Arie, recipimus a domno Laurentio abbate et fratribus Ursarie hereditatem quam habebant in grangia que dicitur Mato que est in Camesia,... $\rangle^{47}$.

En este caso disponemos de más información que en el caso anterior, que nos permite reafirmar el carácter morisco de su protagonista ya que de lo contrario

\footnotetext{
${ }^{44}$ ROMANÍ MARTÍNEZ, Miguel, Colección diplomática do mosteiro de Santa María de Oseira I, doc. 42, 50-51.

${ }^{45}$ Idem, Colección diplomática do mosteiro de Santa María de Oseira I, doc. 113, 124.

${ }^{46}$ Idem, Colección diplomática do mosteiro de Santa María de Oseira I, doc. 144, 148-49.

${ }^{47}$ Idem, Colección diplomática do mosteiro de Santa María de Oseira I, doc. 151, 155-56.
} 
difícilmente se podría entender que un musulmán no converso, acompañado de cristianos, aforara a un monasterio como el de Santa María de Oseira bienes por los que además de pagar cierto canon foral debía convertirse en «vassalli fideles monasterii Ursarie», es decir, en vasallo fiel del monasterio.

Su presencia en la documentación del monasterio de Oseira es relativamente importante porque de nuevo aparece citado, esta vez como testigo, en otros dos documentos.

El primero de ellos es una donación que Azenda Pérez realiza en favor del monasterio y de su abad, de todo lo que poseía en el lugar de Partovia. Esta donación tiene lugar en el mes de enero del año 1229 y, como ya hemos dicho, entre los testigos aparece Petrus Maurus ${ }^{48}$.

El segundo de los documentos, con fecha de 17 de marzo de 1232, consiste en una avenencia entre María Luci y sus hermanos con el monasterio de Oseira sobre unas heredades en Buciños y en ella de nuevo aparece Petrus Mauri como testigo ${ }^{49}$.

Otro ejemplo de musulmán muy probablemente converso, que se encuentra en la documentación de Oseira, es de el Fernandus Mauri, que aparece como testigo en una donación realizada el 22 de septiembre de 1217 por el «milite» Fernando Alfonsi en favor del citado monasterio. En este caso destacaremos el hecho de que aparece en la misma columna de testigos que varios sacerdotes y un monje del monasterio de Oseira ${ }^{50}$.

Casi un año después, concretamente el 29 de agosto de 1218, nos encontramos con un caso ciertamente extraordinario ya que nos hallamos ante un morisco que ocupa un puesto relevante en Ribadavia, como juez en esa villa ${ }^{51}$. Se trata de Lupo Fernandi Mauro $^{52}$ que aparece como testigo cualificado en la venta que María Peláez y sus hijos realizan a Pedro García, encargado de la granja que el monasterio cisterciense de Oseira tenía en Santa María do Burgo.

La utilización del término mauro nos indica su origen religioso y racial y el hecho de que ocupe un cargo como el de juez de la villa de Ribadavia nos indica, junto al uso de nombre cristiano, su conversión al cristianismo, ya que un musulmán no converso no tenía acceso a cargos de responsabilidad pública. Este sería un

\footnotetext{
${ }^{48}$ Idem, Colección diplomática do mosteiro de Santa María de Oseira I, doc. 312, 304-05

${ }^{49}$ Idem, Colección diplomática do mosteiro de Santa María de Oseira I, doc. 352, 339.

${ }^{50}$ Idem, Colección diplomática do mosteiro de Santa María de Oseira I, doc. 171, 172-73.

${ }^{51}$ Idem, Colección diplomática do mosteiro de Santa Maria de Oseira I, doc. 181, 181-82.

${ }^{52}$ Frente a la posibilidad de mantener el apodo en minúscula, el autor y transcriptor, ha optado por presentarlo en mayúsculas, destacando así su consideración de apellido.
} 
caso muy notable de la integración musulmana conversa en la sociedad medieval galaica, aunque con un carácter extraordinario.

Seis años más tarde volvemos a encontrar lo que suponemos una nueva referencia a este juez de Ribadavia, esta vez como propietario de una viña. Su nombre se cita en el testamento que Pedro Fernández hace antes de tomar los hábitos por el que entrega al monasterio de Oseira, el 20 de mayo de 1224, varias viñas: «Mando super vineam quam dedi ad forum Petro Fernandi in sancto Stephano et super aliam que iacet iuxta ecclesiam sancti Stephani et iuxta vineam Lupi Mauri et super alias duas quas ibidem habeo iuxta casale sancte Marie Ursarie» ${ }^{53}$.

Es de suponer que este mismo personaje es el que aparece en un documento datado el 22 de agosto de 1252 en el cual se refleja una concordia establecida entre el abad del monasterio de Santa María de Oseira y los hijos de Pedro Fernández de Ribadavia sobre la herencia de Lupi Fernandi, dicti Mauri ${ }^{54}$.

En el año 1225, muy posiblemente en tierras del Deza, nos encontramos con otro ejemplo de un musulmán, que firma, con su hijo, una cesión de derechos sobre el lugar de Fonselle que realiza Sancha Gómez en favor de su hermana Urraca Gómez: «Petrus Maurus de Ribas, Pelagius Petri filius iam dicti Petri Mauri qui venit integrare iam dictum montem $\rangle^{55}$. Aunque tampoco podamos aseverar su naturaleza conversa, lo cierto es que el hecho de que presente nombre cristiano, muy probablemente de bautismo y que vaya asociado con el apellido de maurus; que su hijo presente nombre y apellido cristianos, siguiendo el sistema antroponímico cristiano y que aparezca como testigo al lado de testigos cualificados (clérigos y monjes de Oseira), nos hace pensar en que realmente se trate de un morisco.

Un caso realmente curioso es el de un testigo de un aforamiento que Juan Fernández y su hermano Velasco realizan en favor de Pedro Abril de una heredad en Saramugueira, en tierras de la Alta Limia orensana, datada el 12 de marzo de 1232. El citado testigo firma como Petrus christiano, nombre cuando menos sorprendente para un cristiano. Desechando como improbable que se trate de un cristiano «viejo», lo único que nos queda es la posibilidad de que se trate de un converso que usó este calificativo para identificarse en una sociedad de cristianos como cristiano-converso, como recientemente bautizado.

${ }^{53}$ Idem, Colección diplomática do mosteiro de Santa María de Oseira I, doc. 249, 246-47. Sobre la utilización del término mauri véase la nota anterior.

${ }^{54}$ Idem, Colección diplomática do mosteiro de Santa María de Oseira I, doc. 689, 648-49.

${ }^{55}$ Idem, Colección diplomática do mosteiro de Santa María de Oseira I, doc. 262, 260-61. 
Lo que sí es más complicado de dirimir es la cuestión de si se trata de un judío o de un morisco converso, pues la información del documento es demasiado escueta.

En una venta, datada en el año 1239, realizada por Goncina Iohanis, su esposo Fernando Uallino y su hermano Iohane Iohanis en favor de Lupo Suerii y de su mujer Urraca Garsie, de una heredad situada en la jurisdicción de San Martín de Ladrones, aproximadamente en el territorio del actual ayuntamiento pontevedrés de A Cañiza, se encuentra entre los testigos Iohanes Arie morrisco ${ }^{56}$. Esta es la primera cita documental en la que un musulmán converso se define como morisco.

También en 1239, pero en la documentación del monasterio de San Martiño Pinario de Compostela, nos encontramos otro morisco. Se trata de la donación que hacen Mayor Menendi y otra persona más de una propiedad en tierra de Cordeiro (Pontevedra) que ya su padre había donado al monasterio. Entre los testigos aparece Fernandus Petri dictus Maurus ${ }^{57}$, a quien suponemos ya bautizado, porque tiene nombre y apellido cristiano además de poseer un apodo relativo a su antigua procedencia.

Un esquema similar se repite en el caso de Garsia Petri, dictus Mauro quien el 2 de agosto de 1258 dona al monasterio de San Salvador de Vilanova de Lourenzá (Lugo) todas las propiedades en el casal de Outeiro y en la villa de Cabarcos. No cabe duda de su naturaleza morisca ya que, además de su nombre cristiano, realiza una donación a un monasterio para remedio de su alma ${ }^{58}$.

Alguien podría pensar que en este caso la utilización del término maurus no se referiría a su antigua condición racial o religiosa de musulmán sino a una característica corporal, como el color de pelo o de la piel, mas no se han encontrado

56 «1239. De Sancto Martino. In Dei nomine. Ego Goncina Iohanis cum uiro meo Fernando Uallino et cum germano meo Iohane Iohanis ... uobis Lupo Suerii et mulieri uestre Urrace Garsie .. uendimus ... leyras quas habemus in Sancto Martino inter remoyno et asuessadas iuxta riparium .. pro pretio ... XL solidiset pro robore $\mathrm{II}^{\mathrm{o}}$ solidis ... Facta carta in e. ${ }^{\mathrm{a}} \mathrm{M} .{ }^{\mathrm{a}} \mathrm{CC} .{ }^{\mathrm{a}} \mathrm{LXX} .{ }^{\mathrm{a}} \mathrm{VII} .{ }^{\mathrm{a}}$ et quotum mense iulii. Regnante rege domno Fernando rege in Castella et Legione. Episcopo in Tuda Stephano. Tenentes castellum Sancti Martini domno Iohane Suerii et domno Ruderico Petri. Martinus Iohanis ts. Iohanes Arie morrisco ts. Michael Petri iudez personaius ad istam cartam faciendum et est testis. Fernandus Suerii notarius de Burgo qui notuit per mandatum personarii qui istam cartam fieri iussit». FERRO COUSELO, Xesús. (transcriptor) y FERNÁNDEZ REY, Aser Ángel (editor), «Tumbo de Fiaês», Boletín Auriense, Anexo 20, Ourense 1995, doc. 259, 169.

${ }^{57}$ LUCAS ÁLVAREZ, Manuel, El monasterio de San Martiño Pinario de Santiago de Compostela en la Edad Media, Compostela 2003, doc. 96, 256.

${ }^{58}$ RODRÍGUEZ GONZÁLEZ, Ángel y REY CAÍÑA, José Ángel, «Tumbo de Lorenzana», doc. 165,205 .

Cuadernos de Estudios Gallegos, Tomo LI, Fascículo 117, Santiago 2004. (Págs. 281 - 312) 
ejemplos de la utilización de estos términos que no hagan referencia a un antiguo pasado musulmán.

Apodar a un cristiano como moro o judio debía de ser considerado como un verdadero atentado contra la propia naturaleza de la persona ya que implicaba equipararlo con los infieles, algo inaceptable en una sociedad como la medieval galaica, en la que ser cristiano se convirtió en un denominador común a la persona. Lo que sí existe en nuestra documentación es la utilización de ciertas variantes de este término aplicados a animales, fundamentalmente a caballos.

Otro ejemplo de la utilización como sobrenombre de un indicativo de la pasada condición de musulmán lo encontramos en un arrendamiento, datado el 19 de julio del año 1260, en el cual el monje-granjero que el monasterio de Oseira tenía en la villa de Ribadavia, llamado fr. Martín, realiza de dos casas ubicadas en la citada villa a «Martini Petri dicto Nigro et uxore vestre Marine Iohannis»"

Como en otros casos anteriores, la utilización de este tipo de sobrenombre recuerda ese pasado musulmán al que nos referimos al principio y el hecho de que se trata de un musulmán converso, es decir, de un morisco, además de poseer un nombre cristiano y ese sobrenombre, se refrenda en el hecho de que está casado con una cristiana, no sabemos si anteriormente conversa o no, ya que no hay ningún tipo de calificativo que acompañe su nombre.

Casi a finales de este siglo XIII, el 7 de noviembre de 1292, se produce la venta de una heredad hecha por María Martínez a don Juan Martínez, prior del monasterio de Santa María de Ribeira. Al igual que en el caso anterior, entre los testigos, aparece un Martin Peres, dito Mouro ${ }^{60}$, es decir, otro ejemplo de la conservación como sobrenombre de la referencia a su antigua condición musulmana.

Aproximadamente en estas fechas, pero en un territorio más norteño, nos encontramos nuevas referencias a la existencia de moriscos. En un apeo de siervos y posesiones del monasterio de San Salvador de Lourenzá, entre los que habitan el lugar de Celeiro de Mariñaos, se cita a «Johanne Mouro et Cipriano Mouro» y a «Petro Mauro et Pelagio Mauro» ${ }^{61}$. De nuevo asistimos a la toma como nombre de bautismo de un nombre cristiano y como apellido o apodo la referencia a su pasado más inmediato, a su origen musulmán.

${ }^{59}$ ROMANÍ MARTÍNEZ, Miguel, Colección diplomática do mosteiro de Santa María de Oseira II, doc. 869, 830-31.

${ }^{60}$ SÁEZ SÁNCHEZ, Emilio, «El monasterio de Santa María de Ribeira», Hispania, t. IV, $\mathrm{n}^{\circ}$ XV, Madrid 1944, doc. 16, 199-200.

${ }^{61}$ RODRÍGUEZ GONZÁLEZ, Ángel. y REY CAÍÑA, José Ángel, «Tumbo de Lorenzana», doc. 13,43 .

Cuadernos de Estudios Gallegos, Tomo LI, Fascículo 117, Santiago 2004. (Págs. 281 - 312) 


\section{MORISCOS Y MUDÉJARES EN LA GALICIA DE LA BAJA EDAD MEDIA}

Ya en el siglo XIV, concretamente el 5 de diciembre del año 1307, en la documentación de San Martiño Pinario, encontramos la noticia de una morisca a través de la presencia como testigo de su hijo en un aforamiento realizado por el abad García Fernández, del monasterio de Cálogo en Pontevedra ${ }^{62}$. En este documento aparece como testigo, con lo que esto implica y que ya hemos comentado en otro caso anterior, un vecino de la localidad en la que está asentado el monasterio, llamado Domingo Pérez al que se le añade «dito da negra», haciendo referencia este calificativo negra al origen musulmán, en este caso, de su madre.

Con la información que nos ofrece el documento no podemos asegurar la caracterización de la madre como mudéjar o morisca pero sería muy extraño que el hijo de una musulmana fuese cristiano y jurídicamente libre (y en este documento Domingo Pérez lo es) y apareciera firmando documentos como testigo al lado de refrendatarios relativamente cualificados como puede ser el caso de Gil Domínguez, clérigo de San Fiz de Loio o Alfonso Pelaiz de Lóngara, escudero.

Será a partir de la primera mitad del este siglo XIV el momento en el que los monarcas castellano-leoneses se preocupen realmente por la presencia musulmana en territorio cristiano, por lo que es común que en las Cortes que se celebran durante este siglo se regulen distintos asuntos relativos tanto a los mudéjares como de los conversos o moriscos. Uno de los aspectos que más nos interesan es la regulación de la utilización de nombres cristianos por parte de los musulmanes peninsulares.

En principio, como hemos visto, no existen impedimentos para que los conversos puedan tomar un nombre y apellido cristiano, a veces conservando su nombre musulmán como sobrenombre; un nombre cristiano y un apellido que hace referencia a su origen musulmán o, en otros casos muy ocasionales, manteniendo su nombre musulmán. Por lo que se refiere al caso de los mudéjares, las Cortes castellano-leonesas prohibirán que estos musulmanes tomen nombre cristiano sin haberse bautizado y convertido al cristianismo.

Aunque hasta ahora hemos podido ver cómo era real la presencia de población morisca en el territorio galaico, lo cierto es que también podemos rastrear la existencia de población mudéjar, de cautivos de guerra musulmanes que suelen ser utilizados como siervos en las labores agrícolas o domésticas. Así el 29 de sep-

${ }^{62}$ LUCAS ÁlVAREZ, Manuel. El monasterio de San Martiño Pinario, doc. 146, 314-15.

Cuadernos de Estudios Gallegos, Tomo LI, Fascículo 117, Santiago 2004. (Págs. 281 - 312) 
tiembre del año 1359 el rey Pedro I confirmaba los derechos que el monasterio de Santa María de Oseira tenía sobre ciertos siervos musulmanes cautivos y sus descendientes que habían abandonado las tierras que debían cultivar por el monasterio.

En la apelación previa del abad de Oseira al rey se hace constar que «ellos que ovieron et an mouros et mouras cativos et fijos et nietos de los dichos mouros, que son siervos de la dicha orden et del dicho monesterio, que les fasen sus lavores et que les fasen menester en su monesterio». A continuación añade el motivo real de la queja que no es otro que «algunos de los dichos siervos que se fueron del dicho monesterio furtadamente a otras partes contra voluntad de los dichos abbad et conviento, et que algunos de vos et otros algunos de los dichos logares que los anparan et los defienden a ellos et a lo suyo, et por esta rason que les non pueden aver nin cobrar para se servir dellos et de lo que an, assi commo an menester ${ }^{63}$.

Este caso podría resultar paradigmático sobre cuál podría ser la situación social de los musulmanes no conversos en tierras galaicas. Aparentemente no se diferenciaría mucho de los cristianos sometidos al solar señorial. Con todo, en este documento se deja entrever la pervivencia de viejos esquemas sociales en los que la adscripción a la tierra y la dependencia del siervo respecto de su señor es prácticamente plena «todos los omes desta guissa son siervos que ellos et todo lo que an que son de sus sennores et los non puede otro ninguno aver sin voluntad de su sennor ${ }^{64}$.

Para terminar este recorrido histórico por ejemplos de la presencia musulmana, mudéjar o morisca, en territorio galaico presentamos a continuación el caso de una comunidad de moriscos asentados en el Val do Ouro lucense a finales del siglo XV que reciben de la reina Isabel I de Castilla a través de Álvaro de Torres, alcaide del castillo de Castro de Ouro, unas telas para la confección de distintos ropajes. Por su indudable interés procedemos a la inclusión de su trascripción y análisis.

El primero de los pagos realizados por el Gonzalo de Baeza, tesorero de la Reina Católica, a Álvaro de Torres, tiene fecha del 13 de febrero de 1492 y estable-

${ }^{63}$ ROMANÍ MARTÍNEZ, Miguel, Colección diplomática do mosteiro de Santa María de Oseira III, doc. 1754, 282-83.

${ }^{64}$ Esta pervivencia de viejos modelos de dependencia servil, creemos que también se puede encontrar referida a cristianos pues suponemos que esa es la condición de los siervos que huyen de las tierras del monasterio de Santa María de Oseira y que son obligados a regresar a ellas por una carta real de Alfonso XI otorgada el 23 de julio de 1345 en Santiago y confirmada en Burgos, en el mes de abril de 1360, por el rey Pedro I. Con todo, la referencia explícita a siervos, cristianos o no, en un momento tan tardío no puede considerarse como la regla sino como la excepción. ROMANí MARTÍNEZ, Miguel, Colección diplomática do mosteiro de Santa María de Oseira III, docs. 1630 y $1757,191-92$ y $285-86$. 
ce que: «Por otra çedula, firmada de la Reyna, fecha 13-II del dicho año, a Aluaro de Torres, alcayde del Castro de Oro, 10.000 mrs., para que los reparta a çiertos [moros] que se tornaron cristianos, para ayuda de su mantenimiento e cosas menudas de su vestuario» ${ }^{65}$.

Justo dos meses después de esta primera entrega se produce la segunda, esta vez de una cantidad mayor ya que va destinada al pago de la confección de ropajes para la totalidad del grupo: «Por vna nomina, firmada de la Reyna, fecha a 13-IV del dicho año, $77.538 \mathrm{mrs}$ e medio, que dicho tesorero dio e pago, por mandado de su Altesa, por çierto paño e seda e lienço e otras cosas, que su Altesa mando dar a Aluaro de Porras (sic), alcayde de Castro de Oro, para dar de vestir a diez e ocho personas, hombres e mugeres e moços, que heran moros e se tornaron cristianos, lo qual todo recibió el dicho Aluaro de Torres en esta guisa: 41 varas de paño de Londres, morados e verdes, para sayas e capuces e sayos, que costo $400 \mathrm{mrs}$. la vara, 18.450 mrs.; 42 varas de paño negro florete de cordovan, para dose mantillos de mugeres, que costo $400 \mathrm{mrs}$ la vara, $16.800 \mathrm{mrs}$; 77 varas e media de paño pardillo de Segouia, para faldillas e sayas, a cinco reales la vara, $12.012 \mathrm{mrs}$. e medio; ocho varas de frisa, para aparejos de los dichos briales, a $50 \mathrm{mrs}$. la vara, 400 mrs.; 20 varas de paño azul de palmilla, para quatro sayas, a ocho reales la vara, $4.960 \mathrm{mrs}$; ; seys varas de cebti negro, para quatro sayuelos de quatro mugeres, a $500 \mathrm{mrs}$. la vara, $3.000 \mathrm{mrs}$.; media vara de terçiopelo negro, para medias mangas e vn collar de vn jubos, que costo a 400 mrs.; 192 varas de lienço de Bretaña, para camisas a todos, que costo a $35 \mathrm{mrs}, 6.720$; dos jubones de fustan, para dos honbres, que costaron 21 reales, quatro jubones para quatro, $1.333 \mathrm{mrs}$; dos pares de calças coloradas, para los dichos dos hombres, 713 mrs.; costaron tondir los dichos paños de Londres, a seys mrs. la vara, e el paño negro a seys mrs. la vara, e el paño pardillo e palmilla, a quatro mrs. la vara, montan $850 \mathrm{mrs}$; que costaron hazer las ropas, con todo por cada brial, a $50 \mathrm{mrs}$., e por las faldrillas, a $40 \mathrm{mrs}$., e por los mantos, a $30 \mathrm{mrs}$, con el lienço que entro en los aparejos de los dichos briales, 1.900 mrs.; que monta todo lo susodicho los dichos $77.538 \mathrm{mrs}$. e medio» ${ }^{66}$.

Apenas transcurrido un mes, de nuevo nos encontramos con un nuevo y cuantioso desembolso destinado a este grupo, a esta pequeña comunidad de moriscos, asentada en las tierras alfocenses del Castro de Ouro: «Por vna nomina de la Reyna, fecha a 8-V del dicho año, 63.204 mrs., quel dicho tesorero dio e pago, por manda-

${ }^{65}$ SIMANCAS, A.G. Contaduría Mayor, leg. 15, fol. 46-2. Publ. TORRE, Antonio y TORRE, E.A. de la, Cuentas de Gonzalo de Baeza: tesorero de Isabel la Católica II, Madrid 1956, 11.

${ }^{66}$ SIMANCAS, A.G. Contaduría Mayor, leg. 15, fols. 48 2v-49. Publ. TORRE, Antonio y TORRE, E.A. de la, Cuentas de Gonzalo de Baeza: tesorero de Isabel la Católica II, 16-17. 
to de su Altesa, por çierto paño e seda e lienço e otras cosas que su Altesa le mando dar a Aluaro de Torres, alcayde de Castro de Oro, para dar de vestir a 18 personas, hombres e mugeres e moços, que heran moros e se tornaron cristianos, e demas de otras 18 personas que se vestieron por otra parte, e se dio al dicho Aluaro de Torres, según se contenia en otra nomina, en esta guisa: 34 varas de Londres, de todas colores, para sayos e capuses e sayas, a 450 mrs. la vara, montan $15.300 \mathrm{mrs}$.; 35 varas de paño florete negro, de Cordova, para mantyllas de mugeres, a $400 \mathrm{mrs}$. la vara, que montan $14.000 \mathrm{mrs}$.; 60 varas de paño pardillo, de Segouia, para faldrillas e sayos, que costo a cinco rreales la vara, monta $9.300 \mathrm{mrs}$.; 36 varas de palmilla azul, para sayas, que costo $240 \mathrm{mrs}$. la vara, que monta $8.928 \mathrm{mrs} ; 154$ varas de Bretaña, para camisas a todos, que costo a $35 \mathrm{mrs}$. la vara, monta 5.390; cinco varas de terciopelo, las quatro varas e media para tres sayuelos de mugeres, e media vara para medias mangas e collar de vn jubón, a $800 \mathrm{mrs}$. la vara, que son 4.000 mrs.; dos varas de rraso negro, para vn jubos, que costo a $500 \mathrm{mrs}$. la vara, $1.000 \mathrm{mrs}$; cinco de fustan, que costaron $1.550 \mathrm{mrs}$., los quatro jubones para hombres 44 reales, e vno para vn mochacho, seys rreales; ocho varas e media de frisa, para aparejos de los briales, a $50 \mathrm{mrs}$., la vara, $425 \mathrm{mrs}$.; dos pares de calças, para dos hombres, que costaron $713 \mathrm{mrs}$.; costaron tundir los dichos paños a seys mrs. la vara e el paño pardillo e las palmillas, a quatro mrs. la vara, que monta en todo ello, con el dicho paño negro, a seys mrs. el tundir por vara e el paño pardillo e las palmillas, a quatro mrs., que monta en todo ello, con el dicho paño negro, a seys mrs. el tundir por vara, 798 mrs.; que costaron el faser todas las dichas rropas, contando por cada brial a $50 \mathrm{mrs}$. e por las faldrillas a $40 \mathrm{mrs}$. e por las manos a 30 mrs., con el lienço que entro en los aparejos de los dichos briales, e con seys rreales de hechura del dicho jubón de rraso, con los aparejos, e por los capuces, a $40 \mathrm{mrs}$. por cada vno, e por los sayos a $50 \mathrm{mrs}, 1.800 \mathrm{mrs}$; que monta todo lo suso dicho, que así recibió el dicho Aluaro de Torres, las dichas $63.204 \mathrm{mrs} .{ }^{67}$.

Por último, el 5 de junio de este año de 1492, se recoge el último de los pagos ordenados por la reina con destino a sufragar, caritativamente, la vestimenta ahora sólo de tres mujeres y de tres muchachas: «Por vna nomia de la Reyna, fecha a 5VI del dicho años, $15.069 \mathrm{mrs}$., quel dicho tesorero dio e pago, por mandado de $\mathrm{Su}$ Alteza, por çierto paño e lienço que dio a Aluaro de Torres, alcayde de Castro de Oro, para vestir a tres mugeres e a tres niñas, que heran moras e se tornaron cristianas, en esta guisa: Diez varas e media de paño negro florete de Cordova, para tres

${ }^{67}$ SIMANCAS, A.G. Contaduría Mayor, leg. 15, fols. 49 2v-50v. Publ. TORRE, Antonio y TORRE, E.A. de la, Cuentas de Gonzalo de Baeza: tesorero de Isabel la Católica II, 18-19. 
mantillos, a $400 \mathrm{mrs}$. la vara, que son $4.200 \mathrm{mrs}$. veynte e quatro varas de paño de palmilla, para seys briales, que costo a ocho reales la vara, que son $5.952 \mathrm{mrs}$. vrese varas de paño pardillo de Segouia, para quatro faldrillas, que costo a çinco reales la vara, que son 2.015 mrs. quatro varas de frisa para los aparejos, a dos reales la vara, $248 \mathrm{mrs}$. cinquenta e quatro varas de bretaña, para camisas, a 35 mrs. la vara, que son 1.890 mrs. para el tundidor de hechuras de los susodichos, $764 \mathrm{mrs}$. que son conplidos los dichos $15.069 \mathrm{mrs}$. en la manera que dicha es» ${ }^{68}$.

Actualmente desconocemos cuál es la causa de que una pequeña comunidad de moriscos aparezca asentada en las estribaciones norteñas de la actual provincia de Lugo aunque sí se puede proponer algunas hipótesis.

El hecho cierto es que se trata de un pequeño grupo, de al menos dieciocho miembros, donde hay hombres, mujeres y niños que reciben telas o vestimentas por orden de la reina Isabel I de Castilla a través de su tesorero Gonzalo de Baeza y del alcaide del castillo de Castro de Ouro, Alvaro de Torres. Desde aquí se abre un conjunto de posibilidades.

La primera de las opciones sería que hubieran vivido en la zona como mudéjares y que al bautizarse hubieran recibido de la reina, en contraprestación, esta dádiva. En contra de esta hipótesis se puede apuntar el hecho de que no haya rastro documental anterior; y a su favor, el hecho de que esta táctica de fomentar la conversión de mudéjares a través de ciertos incentivos como la entrega de vestimentas, será empleada profusamente en el territorio granadino desde, aproximadamente, el periodo 1499-1501. No podemos olvidar que los mudéjares, al igual que los judíos que vivían en territorio cristiano, eran dependientes personales de la Corona y quedaban bajo su protección, teniendo ésta incluso la obligación religiosa y legal de fomentar la conversión voluntaria de estos infieles al cristianismo.

La segunda hipótesis es que fueran mudéjares capturados en la Vega de Granada por algún caballero de la zona y que después se los hubiera traído como siervos, algo también relativamente común en la época. A favor de esta hipótesis está el hecho de la presencia de varios caballeros de la zona en la guerra granadina, como Ruy Díaz de Andrade o Fernán Ares de Saavedra, ambos emparentados con el mariscal Pedro Pardo de Cela, verdadero señor del Castro de Ouro hasta su muerte en el año 1483.

La tercera de las posibilidades es que fueran artesanos mudéjares contratados para la realización de las obras de reparación del castillo de Castro de Ouro y que

${ }^{68}$ SIMANCAS, A.G. Contaduría Mayor, leg. 15, fols. 55-55v. Publ. TORRE, Antonio de la y TORRE, E.A. de la, Cuentas de Gonzalo de Baeza: tesorero de Isabel la Católica II, p. 30. 
se hubieran convertido en este periodo ${ }^{69}$. Tras la caída del mariscal Pedro Pardo de Cela, parece que el gobernador Fernando de Acuña provocó graves daños en la estructura de la citada fortaleza ${ }^{70}$, fortificación que desde ese mismo instante pasó a depender de la Corona como se puede apreciar, por ejemplo, en las «Cuentas de la Hermandad $\aleph^{71}$. No es extraño en esta época constatar la presencia de este tipo de artesanos ambulantes en la realización de esta clase de obras en otras fortificaciones en los distintos territorios de la Corona castellana.

Estas son algunas de las posibles explicaciones que se pueden apuntar acerca del origen, naturaleza y función de esta comunidad morisca asentada en el territorio del Castro de Ouro, en la que se ensayan las medidas de fomento de la conversión de mudéjares que se pondrán en práctica en el reino de Granada varios años más tarde.

\section{CONCLUSIÓN}

A lo largo de estas páginas hemos intentado realizar un recorrido diacrónico a través de parte de la documentación medieval galaica, o relativa a Galicia, fundamentalmente de origen monástica, para presentar una visión general y genérica de la presencia y desarrollo histórico de una minoría étnica como la musulmana, conversa o no, desde las primeras décadas del siglo VIII hasta los últimos años del siglo XV.

Tradicionalmente la opinión más extendida entre los estudiosos de esta minoría étnica era considerar que la presencia musulmana, sobre todo morisca, había sido prácticamente nula en el norte peninsular y particularmente en el caso galaico ésta no se había tenido en cuenta, quizás por ser poco relevante o simplemente por

\footnotetext{
${ }^{69}$ La primera constatación documental que poseemos de la realización de obras de reparación en esta fortificación se retrasa al periodo 1493-1494 y se trata de una asignación que para tal fin se cita en las Cuentas de la Hermandad. Concretamente en esta primera ocasión conocida se destinan un total de 130.000 maravedíes para la «obra de la fortaleza de Castro de Oro». LADEROQUESADA, Miguel Ángel, «La Hermandad en Galicia. 1490-1498», Cuadernos de Estudios Gallegos, 117 (2004).

${ }^{70}$ GONZÁLEZ PAZ, Carlos Andrés. «O Castelo de Castro de Ouro en Alfoz», Actas del Congreso do Patrimonio da Diócese de Mondoñedo, [A Coruña] D.L. 2000, 513-22.

${ }^{71}$ Así en las mencionadas cuentas se puede comprobar como que se le entregan 24.333 maravedíes a Alvaro de Torres, alcaide del Castro de Ouro que expresamente se indica que es «de los reyes». LADERO-QUESADA, Miguel Ángel. «La Hermandad en Galicia. 1490-1498», Cuadernos de Estudios Gallegos, 117 (2004).
} 
participar de la máxima establecida de que en Galicia no existieron moriscos y si alguno hubo fue necesariamente algún esclavo o cautivo de guerra liberado.

Los musulmanes, conversos o no, que vivieron en el territorio galaico, no respondieron a la pluralidad de situaciones económico-jurídicas de la sociedad cristiana, ni se vincularon como los judíos al comercio, a la artesanía o al mundo de las finanzas, sino que, salvo honrosas excepciones, fueron campesinos, casi siempre dependientes, cuyo protagonismo en la historia de Galicia, por poco que haya sido, no puede ser minusvalorado ni silenciado.

No dudamos que en futuros análisis de la documentación editada o en fuentes que en un futuro, más o menos cercano, se editarán, esta nómina de musulmanes, conversos o no, en el territorio galaico aumentará significativamente. Entonces, suponemos, la radiografía de su presencia y protagonismo, más o menos matizado, en la sociedad medieval gallega, podrá perfeccionarse y será más sencillo intentar interpretar cuál fue su verdadero papel.

Creemos que las bases están puestas y que la radiografía de la denominada «cuestión morisca» en Galicia ofrece una casuística rica cuyo análisis, sin duda alguna, nos permitirá ayudar a comprender mejor el desarrollo del proceso de construcción de la sociedad galaica medieval, en la que una mayoría cristiana protagonista permitía que judíos, musulmanes y conversos de ambos credos participaran en el discurrir de la vida diaria, compartiendo con ellos, por lo menos en el plano teórico, las mismas realidades humanas, sociales y jurídicas. 